\title{
Emergence of an Unusual Genotype of Rotavirus in Andaman and Nicobar Islands, India
}

\author{
Rajesh Reesu $^{a} \quad$ Debdutta Bhattacharya $^{a} \quad$ I.K. Chaaithanya ${ }^{a} \quad$ N. Muruganandam ${ }^{a}$ \\ A.P. Bharadwaj ${ }^{b} \quad$ Munni Singhaniac $^{c}$ A.P. Sugunan ${ }^{a} \quad$ P. Vijayachari ${ }^{a}$ \\ ${ }^{a}$ Regional Medical Research Centre (Indian Council of Medical Research), ${ }^{b}$ Chirayu Child Care Centre, and \\ 'G.B. Pant Hospital, Port Blair, Andaman and Nicobar Islands, India
}

\section{Key Words}

Diarrhoea $\cdot$ Rotavirus · Genotype, unusual

\begin{abstract}
s
Rotavirus is the most common cause of severe diarrhoea worldwide, affecting over 125 million young children every year in developing countries. The present study is a part of ongoing childhood diarrhoeal surveillance to determine the strain diversity of rotaviruses prevalent in Andaman and Nicobar Islands. From October 2010 to February 2012, 296 stool samples from children (age group 6-60 months) with gastroenteritis were obtained from different referral hospitals/primary health centres and community health centres in Andaman and Nicobar Islands. A total of 47 samples were found positive for GARV. Among these, 21 (44.7\%) samples belong to G2P[4], 12 (25.5\%) samples were G1P[8], 10 (21.2\%) samples belong to G9P[4], 2 (4.3\%) samples belong to G1P[4] and $2(4.3 \%)$ samples had a mixed genotype. Rotavirus G2 genotype remains the most common genotype in these islands. The prevalence of $\mathrm{G} 9$ rotavirus reported in the present study is higher than that reported from mainland India. The results emphasize the role of the unusual serotype G9 as an epidemiologically important genotype and the need to include G9 specificity in a rotavirus vaccine.
\end{abstract}

Copyright $\odot 2012$ S. Karger AG, Basel

\section{KARGER}

Fax +41613061234

E-Mail karger@karger.ch

www.karger.com
(C) 2012 S. Karger AG, Basel

$0300-5526 / 13 / 0562-0134 \$ 38.00 / 0$

Accessible online at:

www.karger.com/int
Group A rotaviruses (GARV), family Reoviridae, are a major cause of acute infantile diarrhoea in humans worldwide [1]. Globally 527,000 deaths are estimated to have occurred during 2004 due to rotavirus infection [2]. Of the approximately 600,000 annual deaths associated with rotavirus infection worldwide, more than 150,000 occur in India [3]. Twenty-seven G genotypes of rotaviruses are recognized depending on the molecular characterization of VP7 (glycosylated outer capsid protein) [4]. However, G1-G4 are the most predominant genotypes in humans. Moreover, a number of unusual genotypes G5, G8 and G9 have recently also been reported from various countries [5]. Thirty-five $\mathrm{P}$ genotypes are recognized on the basis of VP4 (protease-sensitive outer capsid protein) [4], but the most common $\mathrm{P}$ genotypes infecting humans correspond to $\mathrm{P}[4], \mathrm{P}[6]$ and $\mathrm{P}[8]$ [5]. Although the role of VP4 and VP7 proteins in protective immunity is not very well established, information on G and $\mathrm{P}$ typing is important for identifying unusual or new virus strains circulating in different populations [6]. Epidemiological and molecular studies in many countries show complex patterns of change from one year to the next of rotavirus serotypes associated with diarrhoea in hospitalized children from the same geographical areas [7]. 
Although improvements in sanitation might shift the occurrence of rotavirus infection from younger to older children (i.e. when a child has a more physiological reserve to survive severe gastroenteritis) [8], successful vaccination is the best option to reduce disease burden and mortality not only in Asian populations, in whom the occurrence of rotavirus remains high in early life. Several rotavirus vaccine studies have indicated the need for a polyvalent vaccine candidate encompassing the four epidemiologically important human rotavirus VP7 serotypes, G1-G4 [9].

The Andaman and Nicobar Islands $(\mathrm{A} \& \mathrm{~N})$ is an archipelago of more than 500 islands and islets, stretching over $700 \mathrm{~km}$ from north to south, in the Bay of Bengal. There are 38 inhabited islands with a population of about 380,000 . The islands are connected to mainland India by daily flights from two cities on the mainland and also by ship which leaves from the same cities once a month. The South Andaman district from where the majority of samples were obtained and processed covers an area of 1,348 $\mathrm{km}^{2}$ with a population of 181,949 . An outbreak of diarrhoeal disease caused by GARV, G2P[4] genotype, was reported among the inmates of a temporary relief camp of the Nicobarese affected in the Asian Tsunami of 2004 [1]. Apart from Nicobar, no outbreak of rotaviral diarrhoea has been reported in other parts of these islands.

In this communication we report the data obtained from a preliminary study, undertaken with the objective of identifying the G and P types of GARV presently circulating in the $A \& N$.

From October 2010 to February 2012, stool samples were collected from children (age group 6-60 months) with gastroenteritis attending/being admitted to different referral hospitals, primary health centres and community health centres in $A \& N$. The study was approved by the institutional Ethics Committee of the Regional Medical Research Centre.

Viral double-stranded RNA was extracted from $30 \%$ of the faecal suspensions by using QIAamp Viral RNA extraction kit (Qiagen Sciences, Germantown, Md., USA). The double-stranded RNA was then converted to complementary DNA by reverse transcription polymerase chain reaction (Applied Biosystems, Foster City, Calif., USA) using random primers (Applied Biosystems) and conditions as described by the manufacturer. The complementary DNA was subjected to PCR-based detection of the major capsid protein of rotavirus, VP6 (379 bp) [10]. All the samples positive for VP6 encoding genome segment were further genotyped for VP7 (G) and VP4 (P) by seminested multiplex PCR using specific primers as described earlier [11]. The amplified products were confirmed by sequencing (Genetic Analyzer 3130; ABI, Foster City, Calif., USA) following the manufacturer's protocol (ABI). The raw data were aligned using SeqScape software (Applied Biosystems). Assembled sequences of A\&N G9 strains were aligned with worldwide diverse rotavirus sequences using ClustalW multiple alignment in a pairwise manner for phylogenetic analysis and subsequently analyzed using Kimura's two parameters as a method of substitution and neighbour joining to reconstruct the phylogenetic tree (MEGA version 4.0) [12]. The statistical significance of the relationships obtained was estimated by bootstrap resampling analysis (1,000 repetitions).

Phylogenetic analysis including A\&N G9 strains and international strains from various countries was performed to determine the relationship between A\&N G9 strains and those isolated on other continents.

Between October 2010 and February 2012, a total of 296 samples was collected and processed from patients of the age group of 6-60 months; 47 of these samples were found positive for GARV by reverse transcription polymerase chain reaction of VP6 encoding genome segment. This gives a proportional morbidity for GARV of $15.9 \%$ among children suffering from gastroenteritis in these islands. Rotaviruses with G1, G2 and G9 VP7 encoding genome segment associated with $\mathrm{P}[4]$ and $\mathrm{P}[8] \mathrm{VP} 4$ encoding genome segment were frequently characterized. In this study the most frequent G/P genotype combinations detected were G2P[4], G1P[8] G9P[4] and G1P[4], respectively. Among these, 21 (44.7\%) samples belong to G2P [4], 12 (25.5\%) samples were G1P[8], 10 (21.2\%) samples belong to G9P[4], 2 (4.3\%) samples belong to G1P[4] and $2(4.3 \%)$ samples had a mixed genotype. The distribution of cases by age showed a large peak in children in the age group of 7-12 months from whom 92 (31\%) of the 296 suspected cases were obtained and in whom 20 (43\%) of the 47 cases were confirmed (table 1).

The global impact of rotavirus infection, especially in developing countries, emphasizes the importance of vaccines in the prevention of childhood deaths. Rotavirus serotype diversity and unpredictability from one year to the next and from one region to the next are challenges of vaccine development. Studies so far carried out in India revealed that the predominant strains are G1-G4 [13, 14]. We identified most of the common rotavirus genotypes (G1, G2) with different combinations of $\mathrm{P}[4]$ and $\mathrm{P}[8]$ and the unusual G9 with the combination of $\mathrm{P}[4]$ in our study. However, the rotavirus G2 genotype remains the most common genotype in these islands. The prevalence of G9 rotavirus reported in the present study is 
Table 1. Prevalence of GARV among various age groups with respect to their genotypes

\begin{tabular}{|c|c|c|c|c|c|c|c|}
\hline \multirow{2}{*}{$\begin{array}{l}\text { Age } \\
\text { months }\end{array}$} & \multirow{2}{*}{$\begin{array}{l}\text { Samples } \\
\text { processed (\%) }\end{array}$} & \multirow{2}{*}{$\begin{array}{l}\text { Positivity } \\
\text { rate }(\%)\end{array}$} & \multicolumn{5}{|c|}{ Genotype } \\
\hline & & & $\mathrm{G} 2 \mathrm{P} 4$ & G1P8 & G9P4 & G1P4 & mixed type \\
\hline $0-6$ & $50(17)$ & $3(6)$ & 1 & 1 & 1 & 0 & 0 \\
\hline $7-12$ & $92(31)$ & $20(22)$ & 8 & 7 & 3 & 1 & 1 \\
\hline $13-18$ & $51(17)$ & $9(18)$ & 4 & 2 & 2 & 0 & 1 \\
\hline $19-24$ & 35 (12) & $5(14)$ & 3 & 1 & 0 & 1 & 0 \\
\hline $25-30$ & $25(8)$ & $4(16)$ & 1 & 1 & 2 & 0 & 0 \\
\hline $31-36$ & $14(5)$ & $1(7)$ & 0 & 0 & 1 & 0 & 0 \\
\hline $37-42$ & $11(4)$ & $1(9)$ & 1 & 0 & 0 & 0 & 0 \\
\hline $43-48$ & $10(3)$ & $3(30)$ & 2 & 0 & 1 & 0 & 0 \\
\hline $49-54$ & $4(1)$ & 0 & 0 & 0 & 0 & 0 & 0 \\
\hline \multirow[t]{2}{*}{$55-60$} & $4(1)$ & $1(25)$ & 1 & 0 & 0 & 0 & 0 \\
\hline & 296 & 47 (15.9) & 21 & 12 & 10 & 2 & 2 \\
\hline
\end{tabular}

higher than that reported from mainland India [15]. The genotype G9 strains in this study were recovered from infants in the recognized target age group for rotavirus infection. Interestingly, 4 out of 10 of the infants were hospitalized with GARV G9P[4]; the rest were examined as outpatients. To the best of our knowledge the G9P[4] combination has not been reported from India till now and has very rarely been reported globally. The highest number of suspected and confirmed cases belongs to the age group of 7-12 months. Rotavirus strains that infect neonates may evolve through a process of immune selection and suggest that maternal neutralizing antibodies are important in protecting neonates from rotavirus infection and perhaps disease [16]. But in our study the highest number of cases of GARV is in the age group of 7-12 months, suggesting that there was loss of maternal antibodies in these infants, which made them prone to the infection. Genotype G9 strains (MW69) were first identified in Africa in Malawi between July 1997 and January 1998 [17]. Analyses of the antigenic region revealed point mutation at $242(\mathrm{~T}-\mathrm{N})$ in all African G9 strains. The detection of rotaviruses with the G9 specificity has been reported in the Asian, American, African, and Australian continents at either low or high frequency. In Europe, G9 rotaviruses have been detected sporadically in the United Kingdom, Ireland, France, and Italy [18]. Recent studies on serotype G9 strains have shown that these strains are promiscuous, reasserting with SGI, short electropherotype or SGII, long electropherotype strains, while still maintaining an overall VP7 amino acid identity of $>90 \%$ [19]. Infection with GARV G9 is shown to be associated with more severe disease than infection with
GARV G1, which is still the most common serotype [20]. The Kimura 2 parameter for mean genetic distance among the isolates with G9 genotype from these islands was 0.00 . The Kimura 2 parameter value between the G9 genotype isolates of these islands and that with isolates from Japan (AB091747, AB091748, AB091749, AB091750, AB091751 and AB091752), Eastern India (DQ117937 and AJ491165) and Thailand (AY699291, AY699301, AY699303, AY699304 and GQ149704) was significantly less (Kimura 2 parameter $=0.007$ ) than the isolates from other parts of the world. The significantly less genetic distance among the G9 genotype isolates from these islands compared to that of Japan, Eastern India and Thailand revealed that these strains may have originated in these islands from these three sources (fig. 1).

Serotype G1-G4 strains are considered to be the predominant rotaviruses causing human disease worldwide. Unusual strains are described as prevalent in some locations. For instance, in Brazil one third of infections were with uncommon serotypes, e.g. G5 strains [21]. In the Indian subcontinent, unusual combinations and rare human strains predominated $[15,22]$. The diversity of strains circulating in different regions may be important for vaccine administration and development [23]. The results described here emphasize the role of rotavirus G9 as an epidemiologically important genotype and the need to include G9 specificity in the candidate rotavirus vaccine [18]. The lower efficacy of rotavirus vaccines in some countries is not fully understood and is likely to be due to many factors. One explanation may be that disease is caused by VP7 serotypes not covered by current vaccine candidates. Since reassortant vaccines are engineered to 
Fig. 1. Phylogenetic analysis of the G9 genotype of GARV isolated from these islands. The sample numbers isolated from these islands are BC409-G9 PB, BC522-G9 PB, BC407-G9 PB, SS1023G9 PB, SS1015-G9 PB, SS1031-G9 PB, SS1028-G9 PB, SS3003-G9 PB and DS659-G9 PB.

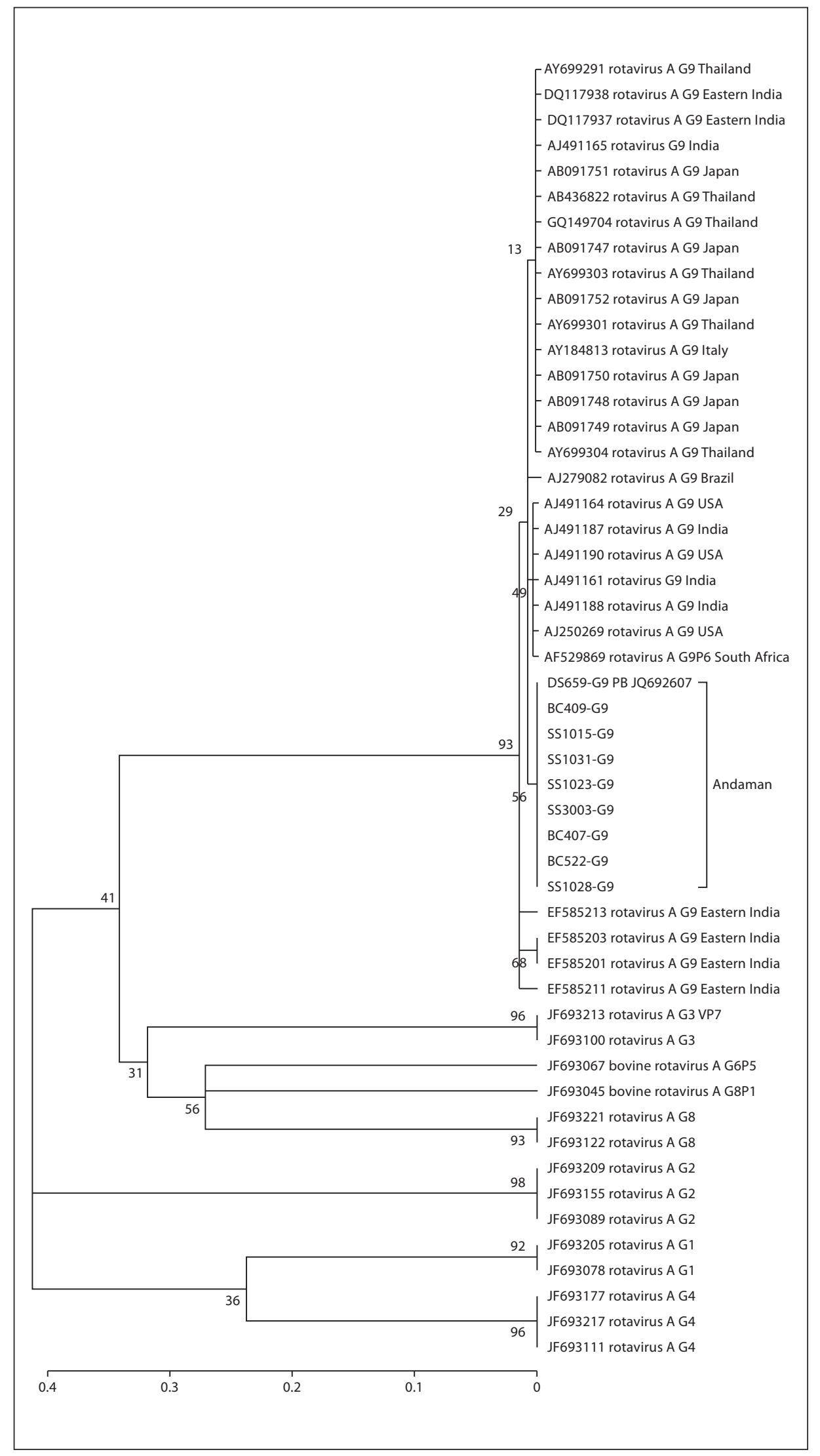

Intervirology 2013;56:134-139 
contain the prevalent $\mathrm{G}$ antigens (i.e. G1-G4), these vaccines may be less protective against unusual strains circulating in these countries that were not incorporated in the formulation of the current vaccines. The global emergence of genotype G9 strains has prompted fears that the current vaccine candidates may not protect against these new genotypes as efficiently as they had shown protection against other common genotypes [24]. Unlike reported earlier, the most common $\mathrm{P}$ genotypes associated with $\mathrm{G} 9$ are $\mathrm{P}[8]$ and, to a lesser extent, $\mathrm{P}[6]$ [22]; we detected $\mathrm{P}[4]$ combination with G9. There is no study reporting the efficacy of the rotavirus vaccine against G9P[4]. In fact, symptomatic reinfection of vaccinated children with G9 has been shown to be possible [24, 25], and as suggested by Phan et al. [26], further classification of G9 strains into lineages and sublineages may aid in the identification of monotypes that escape vaccine-generated immunity.

Continued surveillance is planned to monitor the changes in strain prevalence to better understand virus evolution and the shifting trends of strain patterns over time, which could affect future vaccine strategies that are predicated on the development of serotype-specific immunity to the globally common $\mathrm{G}$ genotypes.

\section{GenBank Accession Number}

We have submitted one sequence of each genotype as there was no single base change among the sequences belonging to each individual genotype, respectively. So we have provided one accession number for one isolate belonging to each genotype. The GenBank accession numbers of our submissions are JQ692605 (P[8]), JQ692606 (P[4]), JQ692607 (G9), JQ692608 (G2) and JQ692609 (G1).

\section{Acknowledgement}

The authors would like to thank the Indian Council of Medical Research (see letter No. 5/8/7/16/2010-ECD-I and No. 5/8$1(209) / D / 2006 / E C D-I I)$ for providing financial grants for this study. They are also grateful to the Directorate of Health Service (Andaman and Nicobar Islands) for their extensive support and help during the work.

\section{Disclosure Statement}

The authors do not have any commercial or other associations that may pose a conflict of interest.

\section{References}

-1 Samajdar S, Ghosh S, Naik TN, Roy S, Sugunan AP: The post-tsunami outbreak of diarrhoeal diseases in Car Nicobar Island, India, was caused by human group A rotavirus G2 strains. J Infect 2008;57:357-359.

2 World Health Organization. Estimated rotavirus deaths for children under 5 years of age: 2004, 527,000. WHO, 2004. http://www. who.int/immunization_monitoring/burden/rotavirus_estimates/en/index.h.

-3 Jain V, Das BK, Bhan MK, Glass RI, Gentsch JR: The Indian Strain Surveillance Collaborating Laboratories. Great diversity of group A rotavirus strains and high prevalence of mixed rotavirus infections in India. J Clin Microbiol 2001;39:3524-3529.

-4 Matthijnssens J, Ciarlet M, McDonald SM, Attoui H, Bányai K, Brister JR, Buesa J, Esona MD, Estes MK, Gentsch JR, Iturriza-Gómara M, Johne R, Kirkwood, CD, Martella V, Mertens PP, Nakagomi O, Parreño V, Rahman M, Ruggeri FM, Saif LJ, Santos N, Steyer A, Taniguchi K, Patton JT, Desselberger U, Van Ranst M: Uniformity of rotavirus strain nomenclature proposed by the Rotavirus Classification Working Group (RCWG). Arch Virol 2011;156:1397-1413. $\checkmark 5$ Cunliffe NA, Gondwe JS, Graham SM, 11 Gouvea V, Glass RI, Woods P, Taniguchi K, Thindwa BDM, Dove W, Broadhead RL, Molyneux ME, Hart CA: Rotavirus strain diversity in Blantyre, Malawi, from 1997 to 1999. J Clin Microbiol 2001;39:836-843.

6 6 Koopman M, Brown D: Seasonality and diversity of group A rotaviruses in Europe. Acta Paediatr 1999;426:14-19.

7 Bishop RF, Masendycz PJ, Bugg H, Carlin JB, Barnes GL: Epidemiological patterns of rotaviruses causing severe gastroenteritis in young children throughout Australia from 1993 to 1996. J Clin Microbiol 2001;39:1085-1091.

-8 Bresee JS, Glass RI, Ivanoff B, Gentsch JR: Current status and future priorities for rotavirus vaccine development, evaluation and implementation in developing countries. Vaccine 1999;17:2207-2222.

-9 Hoshino Y, Kapikian A Z: Rotavirus vaccine development for the prevention of severe diarrhoea in infants and young children. Trends Microbiol 1994;2:242-249.

10 Iturriza Gómara M, Wong C, Blome S, Desselberger U, Gray J: Molecular characterization of VP6 genes of human rotavirus isolates: correlation of genogroups with subgroups and evidence of independent segregation. J Virol 2002;76:6596-6601. Clark HF, Forrester B: Polymerase chain reaction amplification and typing of rotavirus nucleic acid from stool specimens. J Clin $\mathrm{Mi}$ crobiol 1990;28:276-282.

12 Tamura K, Dudley J, Nei M, Kumar S: MEGA4: Molecular Evolutionary Genetics Analysis (MEGA) software version 4.0. Mol Biol Evol 2007;24:1596-1599.

13 Brown DW, Minnie G, Mathan M, Mathew M, Martin R, Beards GM, Mathan VI: Rotavirus epidemiology in Vellore, South India: group, subgroup, serotype and electropherotype. J Clin Microbiol 1998;26:2410-2414.

14 Das S, Sen A, Uma G, Varghese V, Chaudhuri S, Bhattacharya SK, Krishnan T, Dutta P, Dutta D, Bhattacharya MK, Mitra U, Kobayashi N, Naik TN: Genomic diversity of group A rotavirus strains infecting humans in Eastern India. J Clin Microbiol 2002;40: 146-149.

-15 Samajdar S, Ghosh S, Chawla-Sarkar M, Mitra U, Dutta P, Kobayashi N, Naik TN: Increase in prevalence of human group A rotavirus G9 strains as an important VP7 genotype among children in eastern India. J Clin Microbiol 2008;43:334-339. 
16 Ramachandran M, Vij A, Kumar R, Das BK, Gentsch JR, Bhan MK, Glass RI: Lack of maternal antibodies to $\mathrm{P}$ serotypes may predispose neonates to infections with unusual rotavirus strains. Clin Diagn Lab Immunol 1998;5:527-530.

17 Cunliffe NA, Gondwe JS, Broadhead RL, Molyneux ME, Woods PA, Bresee JS, Glass RI, Gentsch JR, Hart CA: Rotavirus G and P types in children with acute diarrhoea in Blantyre, Malawi, from 1997 to 1998: predominance of novel P[6]G8 strains. J Med Virol 1999;57:308-312.

18 Martella V, Terio V, Gaudio GD, Gentile M, Fiorente P, Barbuti S, Buonavoglia C: Detection of the emerging rotavirus $\mathrm{G} 9$ serotype at high frequency in Italy. J Clin Microbiol 2003;41:3960-3963.
19 Page N, Esona M, Armah G, Nyangao J, Mwenda J, Sebunya T, Basu G, Pyndiah N, Potgieter N, Geyer A, Steele AD: Emergence and characterization of serotype G9 rotavirus strains from Africa. J Infect Dis 2010; 202:S55-S63.

20 Linhares AC, Verstraeten T, Bosch JW, Clemens R, Breuer T: Rotavirus serotype G9 is associated with more-severe disease in Latin America. Clin Infect Dis 2006;43:312-314.

21 Gouvea V, De Castro L, Timenetsky MC, Greenberg H, Santos N: Rotavirus serotype G5 associated with diarrhoea in Brazilian children. J Clin Microbiol 1994;32:14081409.

22 Bern C, Unicomb L, Gentsch JR, Banul N, Yunus M, Sack RB, Glass RI: Rotavirus diarrhoea in Bangladeshi children: correlation of disease severity with serotypes. J Clin Microbiol 1992;30:3234-3238.

23 Santos N, Hoshino Y: Global distribution of rotavirus serotypes/genotypes and its implication for the development and implementation of an effective rotavirus vaccine. Rev Med Virol 2005;5:29-56.
24 Vesikari T, Karvonen A, Puustinen L, Zeng SQ, Szakal ED, Delem A, De Vos B: Efficacy of RIX 4414 live attenuated human rotavirus vaccine in Finnish infants. Pediatr Infect Dis J 2004;23:937-943.

25 Vesikari T, Matson DO, Dennehy P, Van Damme P, Santosham M, Rodriguez Z, Dallas MJ, Heyse JF, Goveia MG, Black SB, Shinefield HR, Christie C DC, Ylitalo S, Itzler RF, Coia ML, Onorato MT, Adeyi BA, Marshall GS, Gothefors L, Campens D, Karvonen $\mathrm{A}$, Wat JP, O'Brien KL, DiNubile MJ, Clark HF, Boslego JW, Offit PA, Heaton PM: Safety and efficacy of a pentavalent humanbovine (WC3) reassortant rotavirus vaccine. N Engl J Med 2006;354:23-33.

26 Phan TG, Okitsu S, Maneekarn N, Ushijima $\mathrm{H}$ : Genetic heterogeneity, evolution and recombination in emerging $\mathrm{G} 9$ rotaviruses. Infect Genet Evol 2007;7:656-663. 